\title{
交通基础设施投资对区域经济发展的影响及优化
}

\author{
Impact of Transportation Infrastructure Investment on
}

\section{Regional Economic Development and Optimization}

刘政豪 ${ }^{1}$ 张维烈 ${ }^{2}$

Zhenghao Liu ${ }^{1}$ Weilie Zhang ${ }^{2}$

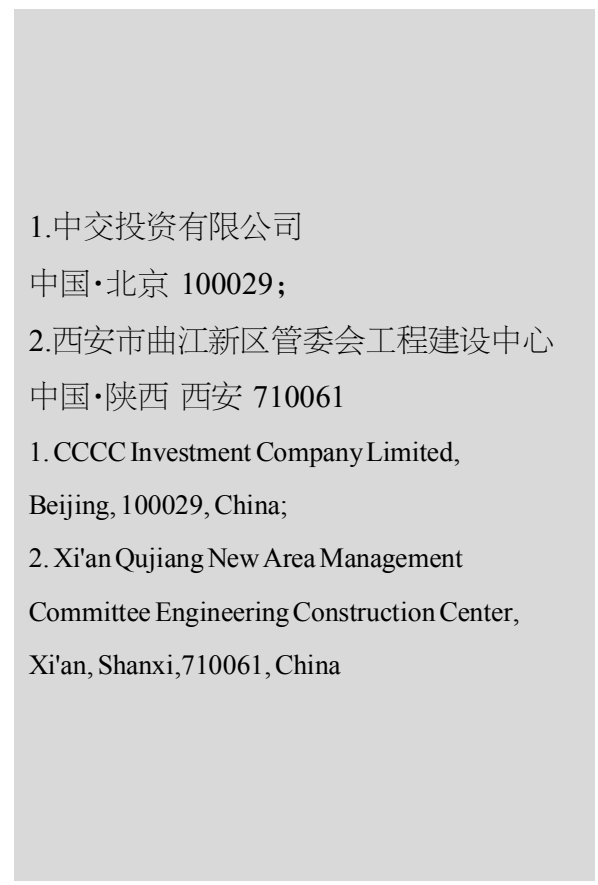

【摘 要】中国国民经济发展水平在不断提升, 交通基础运输在国民经济协调发展中占据 着重要位置, 直接关系着区域经济的发展,这逐渐成为政府部门关注的重点内容。在新时 期的发展中, 交通基础设施投资与区域经济发展之间的联系十分密切,相关部门必须予以 重视,论文主要对交通基础设施投资对区域经济发展的影响及优化进行了分析。

【Abstract】The level of development of China's national economy is constantly improving, and the basic transportation of transportation occupies an important position in the coordinated development of the national economy, which is directly related to the development of regional economy, which has gradually become the focus of attention of government departments. In the development of the new period, the relationship between transportation infrastructure investment and regional economic development is very close, and the relevant departments must pay attention to it. This paper mainly analyzes the influence and optimization of transportation infrastructure investment on regional economic development.

【关键词】交通基础设施投资; 区域经济发展; 影响;优化

【Keywords 】transportation infrastructure investment; regional economic development; impact; optimization

【DOI】10.36012/emr.v2i1.1044

\section{1 引言}

在新经济形势下，基础设施与经济发展之间的联系十分 密切，政府部门需要将基础设施投资作为经济周期调控的基 本手段,刺激区域经济增长, 实现区域经济的协调发展, 交通 基础设施作为基础设施中的关键部门在区域经济协调发展中 发挥着重要作用, 中国交通基础设施存量日益增长,在城市化 建设大力推进的背景下, 经济发展区域性特征明显, 需要深入 分析交通基础设施投资为区域经济增长带来的影响, 为交通 基础设施投资策略的制订提供支持。

\section{2 交通基础设施投资对区域经济的影响}

随着社会经济的快速发展, 交通运输行业取得了很大进 步, 人们越来越关注交通基础设施建设, 交通基础设施属于开 放系统, 区域经济运行发展需要外界资源作为支持, 外界物 质、能量和信息应及时地转换,物质、人力等因素在交通基础 运输中具有重要作用, 但这种作用是双向的, 分别是引导和制 约 ${ }^{[1]}$ 。在交通基础设施条件便利的情况下,会推动区域经济的
发展, 对产业结构、生产布局带来积极影响, 如交通基础设施 条件相对落后, 会影响区域经济的发展, 交通基础设施和区域 土地开发需要共同进行投资、建设,获取更多的效益,实现交 通建设和区域经济的协调发展。在现代化区域经济的发展中, 交通建设属于城市建设中的一部分, 在连接交通建设和其他 产业的情况下,会形成整体联合发展模式,这将成为新时期区 域交通发展的新方向。在区域经济发展过程中, 交通基础设施 投资对区域经济发展带来了深远影响:第一,增加交通基础设 施投资, 满足产业生产部门的各项需求，拉动区域经济的增 长; 第二,交通基础设施投资改善了区域交通供给水平,减少 运输成本的投入, 发挥出区位优势, 并对相关地区、产业发展 带来了一定影响, 推动着区域经济的进一步发展。

\section{3 交通基础设施投资对区域经济发展的} 优化建议

\section{1 调整交通基础设施运输方式}

在社会经济的发展中, 社会各界需要注重经济发展的转 变, 合理地调整经济发展的结构,将国民经济发展外需转变成 
区域经济 Regional Economy

内需, 这就要求改善传统的不合理的经济结构形式,如区域结 构、城乡结构和产业结构, 大力刺激内需, 促进区域经济的快速 发展。因此,在经济结构转变过程中,政府部门需要在交通基础 设施体系的基础上,确保交通运输体系配套, 提高运输的安全 性、便利性, 实现多层次、多元化的货物运输与旅客运输结构。

\section{2 将各种运输方式进行整合}

现阶段, 很多地区的交通运输体系结构缺乏一定的合理 性, 各种运输方式无法协调发展, 交通运输部门需要遵循统一 协调的原则, 做好规划、建设和管理工作, 强化各个部门、运输 方式之间的交流，实现交通设施资源的有效整合。同时,相关 部门在选择交通运输路线的过程中, 需要加强和其他方式的 统筹考虑, 加强各个部门之间的协作, 避免出现恶性竞争 ${ }^{[2]}$ 另外,政府部门在建设运输方式主枢纽节点的过程中, 需要预 留出其他运输方式相关的结构, 加强大、中型城市中心区和城 乡结合部的客运换乘枢纽建设。

\section{3 加大交通基础设施投资力度}

交通基础设施是国家经济发展的重要条件，其完善性与 经济发展速度息息相关, 交通基础设施投资推动着经济增长, 与其他资本相比, 交通基础设施投资效率相对较低,但交通基 础设施建设对促进经济发展具有重要作用，社会各界必须予

\section{（上接第 3 页）}

革应以以下方式开始:建立“双基础”教育,培养具有基础知识 和基本技能的社会工作者, 为发展社会上的一切生活提供足 够的劳动力, 满足社会对基于知识的人才的需求。基础教育多 年来一直追求高分和入学率, 重视理论教育, 导致学生的社会 适应性较差, 理论与实践并不十分吻合。这种基于 “综合分数 和人学率” 的教育目标必须改变, 应着重于应用型人才的培 养, 树立学生的“思想、道德、文化、训练”四个青年意识,加强 学生的道德教育、心理素质、科学知识、创新思维和实践能力。 在智力、艺术和工作领域全面发展的人才新时代, 通过 “素质 教育”和“核心技能教育”, 培养创新型人才、实践型人才和综 合型人才, 为现代化建设提供智力和人才支持。为了树立正确 的观念, 应使用良好的绩效理论, 注意全面提高学生素质和能 力,建立科学的教育质量标准。

\section{3 要树立正确的教学理念}

教师在进行教学的过程中需要认识到学生才是教学的主 体, 在课堂和课外融合发展, 促进学生的自学技能和创造精 神。在提供基础课程和专业课程的前提下，建立一些社会课 程, 例如, 自然课程、职业技术课程、科学技术课程和社会课 程, 以培养社会人才。在教学风格上, 要注重培养学生的自我
以重视, 加大投资建设力度, 加强和上下游相关产业之间的联 系, 确保交通基础设施投资的规范性, 实现交通运输线路的充 分利用,发挥出交通基础设施对区域经济发展的作用。

\section{4 结语}

综上所述, 随着经济社会的快速发展, 交通运输网络与社 会经济可持续发展之间的联系日益密切。交通运输业作为国 民经济发展的支柱产业之一, 在很大程度上推动着国民经济 发展,逐渐成为国家宏观调控的重点 ${ }^{[3]}$ 。现阶段,消费、投资问 题日益严峻, 交通部门应科学规划交通基础设施建设, 深人分 析交通基础设施建设对区域经济带来的影响，交通基础设施 投资使得区域资源和信息流通速度有所提升，有助于各个区 域之间的经济往来,推动着区域经济的快速发展。

\section{参考文献}

[1]吴翼.空间视角下交通基础设施对区域经济的影响研究 [J].物 流工程与管理,2019,41(8):134-135.

[2]姚智美,姜钰羡,肖翔.“一带一路”交通基础设施项目投资的现 状、问题与对策研究 [J].交通财会,2019(8):31-37.

[3] 李晓慧.交通基础设施投资对区域经济发展的影响 [J].北方经 贸,2019(3):128-129.

学习能力、自我管理能力和自我教育能力, 这些能力被认为是 人才满足基本社会需求的一般能力。

\section{4 改进多阶段的人才培训系统}

与学校合作, 培养制造业急需的科研技术复合型人才, 深 化相关领域的工程博士学位和硕士学位课程改革, 促进产学 研结合。加强工业人才需求预测, 完善各种人才信息库, 建立 工业人才水平评价体系和信息披露平台。建立人才激励机制,提 高对优秀人才的奖励。建立和完善制造业人才服务机构,完善人 才流动和使用的制度。学校可以选择称职的人才, 特别是专业技 术人员, 以各种形式进行出国学习培训,建立国际培训中心。

\section{3 结语}

人才是建立强大国家的重要支持, 高校要建立科学合理 的教育机制, 为强国建设提供可持续动力。在新时代, 高等教 育要与时俱进, 建立从理论型到应用型的人才培养体系, 建设 工程培训中心以及先进的专业技术培训中心。此外, 大学应主 动与企业合作, 明确行业需求, 改善课程体系, 提高学生的就 业能力。

\section{参考文献}

[1]冯媛.浅析如何在高校钢琴教育中培养即兴伴奏应用型人才 [J].戏剧之家,2019,313(13):216. 